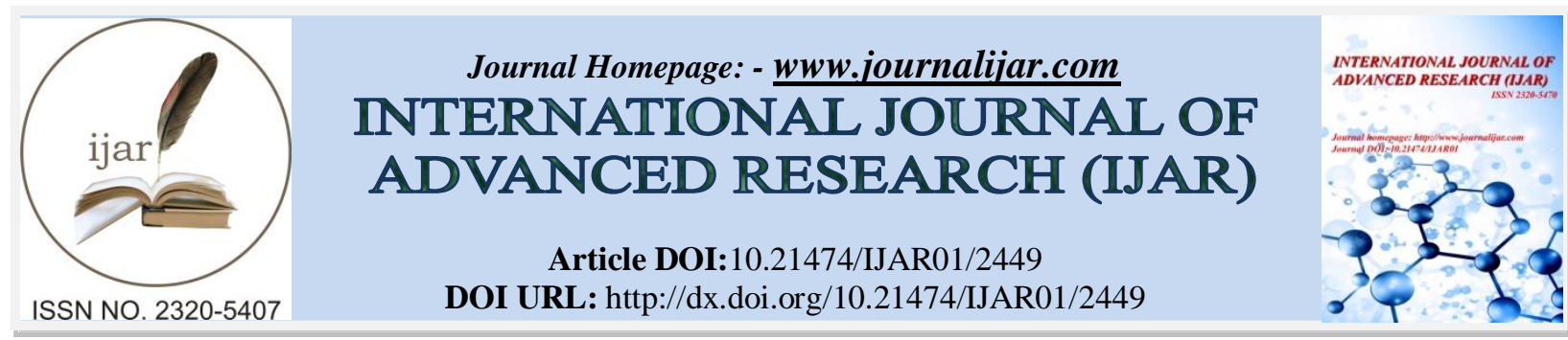

RESEARCH ARTICLE

\title{
FORECASTING OF WHEAT PRODUCTION: A COMPARATIVE STUDY OF PAKISTAN AND INDIA.
}

Dr. Muhammad Iqbal Ch., Muhammad Tariq Jamshaid, Asad AliandQaisar Rashid.

Department of Statistics, University of Sargodha, Sargodha, Pakistan.

\section{Manuscript Info}

Manuscript History

Received: 20 October 2016

Final Accepted: 22 November 2016

Published: December 2016

Key words:-

ARIMA, AIC, SBC, MAE, MAPE,

RMSE.

\section{Abstract}

All investors are eager to know about the trend of wheat production, whether it will increase or decrease. Recently, wheat production has become a hot topic for everyone; it fluctuates rapidly from the past few years. In this study, we propose a time series model for forecasting annual wheat production of Pakistan and India by using secondary data in 1000MT from 1960 to 2015. By using Box-Jenkins methodology, Autoregressive Integrated Moving Average (ARIMA) model is selected and the model selection criterion (AIC and SBC) shows that ARIMA $(1,1,1)$ and $(0,1,1)$ showing good performance in case of Pakistan where ARIMA $(1,1,0)$ and $(0,1,1)$ are good for India's annual wheat production forecast. Forecasted values of ARIMA $(1,1,1)$ and ARIMA $(1,1,0)$ are more accurate for Pakistan and India respectively on the bases of Mean Absolute Error (MAE), Mean Absolute Percentage Error (MAPE) and Root Mean Square Error (RMSE).

Copy Right, IJAR, 2016,. All rights reserved.

\section{Introduction:-}

Agriculture is the backbone of Pakistan's economy and it contributes to the economic and social well-being of the nation through its influence on the gross domestic product (GDP), employment and foreign exchange earnings. Pakistan is an agrarian country where more than $70 \%$ population is directly or indirectly indulged in agricultural activities.

First of all, we must know that what is wheat? Philosopher defined it as, "A cereal which is the most important kind grown in temperate countries, the grain of which is ground to make flour for bread, pasta, pastry, etc."

Wheat industry is a third biggest industry of Pakistan. Along with the wheat producing country, Pakistan stands at 9th position in terms of area (8.5 million hectares) and 59th in terms of yield (21.0 $\mathrm{m}$ ton) annually. It occupies a highest position in the food grains of Pakistan, it covers 66\% of the total area under food grains and contribute 74\% of the total food grain production. Wheat only contributes $13.8 \%$ to the value other in agriculture and $3.4 \%$ towards Gross Domestic Product (GDP) of Pakistan.

Currently, India is third largest producer of Wheat in the world after China with about $12 \%$ share in total world Wheat production. Now, India is surplus and in a position to export Wheat in the International Market and can earn foreign exchange.

Corresponding Author:- Dr. Muhammad Iqbal Ch.

Address:- Department of Statistics, University of Sargodha, Sargodha, Pakistan. 
Wheat is the second-most formed crop on Earth, covering behind only corn. Wheat provides a large portion of the food protein and total food supply, and is grown all throughout the world, in a broad variety of climates. Wheat is afasten crop, grown as a primary food product and for other uses as well. Wheat is perhaps the oldest cultivated plant.

If top countries in wheat production is disturbed, then in top ten countries European Union is at top, it's rate is 157.98 million metric tons. China is at number 2 and its rate is 130.19 million metric tons. Pakistan is at 9th number and its rate is 25.48 million metric tons. India is at $3^{\text {rd }}$ position and its rate is 88.94 million metric tons. As far as in top 10 countries last one is concerned...Turkey is at number ten and its rate is 19.5 million metric tons.

Today, wheat is a grass that grows between 2 and 4 feet ( 0.6 to 1.2 meters) tall. The physical look of the grain is recognizable to most consumers, with a long stalk that terminates in a strongly formed gather of curvy kernels with this by a beard of smooth spikes. The plant is an annual, which means that at the end of each year, fields must be plowed and prepared again to grow the grass. Inherited wheat perhaps looked very different, with much smaller kernels. The early domesticators apparently wanted to select for plants with for the most part large kernels, since more food could be eked out from each stalk. Because wheat is generally a self-pollinating plant, each plant tends to produce clones of itself. When farmers want to hybridize a twist, they must physically pollinate the different plants. Farmer's combination wheat for a variety of purposes usually unites different seeds at harvest time and extends them regularly over the field.In this study, these models were applied to forecast the production of wheat crop in Pakistan. This would enable to predict expected wheat production for the years from 2016 onward.

\section{Literature Review:-}

Muhammad et al. (1992) conducted an empirical study of modeling and forecasting time series data of rice production in Pakistan. ARIMA model has been frequently employed to forecast the future requirements in terms of internal consumption and export to adopt appropriate measures.

Saeed et al. (2000) investigated the study of forecasting for wheat production with considering a variable wheat production. The box Jenkins time series technique is utilized on the data from 1998-2013. The diagnostic checking shows ARIMA $(2,2,1)$ is appropriate. Forecasting from this model show that these forecasts are helpful in future policy makers for agriculture and grain storage and import \& export of wheat production.

Shah et al. (2001) investigated the comparative study of wheat production before \& after chashma right bank canal. Survey data was collected from five villages. The study has assessed variable per acre yield of wheat $\&$ area under wheat production. Two approaches used for this analysis one is $t$ statistics and other is regression analysis. The result show that there is a significance change in per acre yields $\&$ area under wheat production. This result also show that CRBC play an important role in increasing change in wheat production.

Iqbal et al. (2005) investigated the study of wheat production in Pakistan. The study of wheat production determines the forecasting of wheat production in Pakistan up to the year 2022. They used time series technique that is ARIMA model. Considering variable is wheat production. The ARIMA model show that production of wheat would be 29774.8 thousand tons in 2002-22. The possibility of higher area and production lies in enough accessibility of inputs, cultivating and guidance the agricultural group of people, soil protection and recovery, and especially the encouraging government policies concerning wheat promotion in the country.

Karim et al. (2005) applied regression modeling to forecast wheat production of Bangladesh districts. Authors used seven model selection criteria's and found that different models were identified for different districts for wheat production forecasts. They have found that wheat production in Bangladesh districts i.e. Dinajpur, Rajshahi, and Rangpur would be $1.54,0.35,0.31$, and 0.58 million tons, respectively, in 2009/10.

Amin et al. (2014) investigated the study country planning, forecasting is the main tool to determine the situation that would be in the coming years in country. Various time series models were used on this data from (1902-2005) using two software's JMP \& Stat graphics and found that the best model is ARIMA $(1,2,2)$. On the basis of results they conclude that production of wheat in Pakistan would become 26623.5 thousand tons in 2020 and would become double in 2060 compared as 2010. 
Iqbal et al. (2014) analyzed the future situation of economy and trade affairs in four major countries Bangladesh, India, Pakistan and Sri Lanka of SAARC for different commodities during 1970 to 2010, while for Bangladesh the period has been counted from 1972 to 2010.The results expose that India will enjoy top level in the export of cotton, sugar and rice while Pakistan will achieve second level and future export of Bangladesh and Sri Lanka will remain at low level in all the commodities.

Choudhury and Jones (2014) analyzed several forecasting techniques for evaluating crop yield assessments in Ghana to provide useful information for decision making about Ghana's economy. They compared different models (Damped-Trend Linear Exponential Smoothing, ARMA models, Simple and Double Exponential Smoothing) under each district data and found ARMA model more robust (independent from cyclical length) and preferable over other models.

Ali and Jabbar (2015) investigated growth and variation in area, and yield and production of fruit crops (apple, peach, pear, and plum) in Khyber Pakhtunkhwa province based on data from 1975-76 to 2011-12 which is further split into three periods; Period-I (1975-76 to 1990-91), period-II (1991-92 to 2011-12), and period-III (1975-76 to 2011-12). For variability analysis Cuddy-Della Valle index has been used and find out as a foremost contribution of apple, pear and plum is low then peach during Period-I. In period-II as compare to I more variability in fruit production and in Period-I both area under fruit and yield cause of variability in fruit production.

Ramesh (2015) worked on modeling and forecast the production/yield of wheat in India from 1961-2013. Compared different models (Parametric regression, exponential smoothing and ARIMA) to observed trend of wheat production. Found best model ARIMA $(1,1,0)$ on basis of several goodness of fit criteria (Root Mean Squared Error, Mean Absolute Percentage Error, Mean Absolute Error, Mean Squared Error, Akaike Information Criterion, Schwarz's Bayesian Information Criterion and R-squared) and forecasted value 100.271 million tons for 2017-18. They also examined independence and normality assumption through Run test and Shapiro-wilk test respectively.

\section{Methodology:-}

A mystery to know, what happened in the future, the index rises or fall, a forecasting methodology was planned by Box and Jenkins in 1970 named as Box-Jenkins methodology. It is most suitable model selection method for forecasting of time series variable. The Box-Jenkins methodology is valid only when the variable fulfills some assumptions. First of all, variable should be stationary and there is no seasonality, but if the variable violated the assumption or any pattern according to scale or location then the first mission is to make it stationary for applying Box-Jenkins model. Practice shows that most variables are non-stationary in real life so to convert non-stationary variables into stationary variables we obtain the difference of variables and the new variables are known as integrated variable. The Box-Jenkins methodology may be followed by this way: 


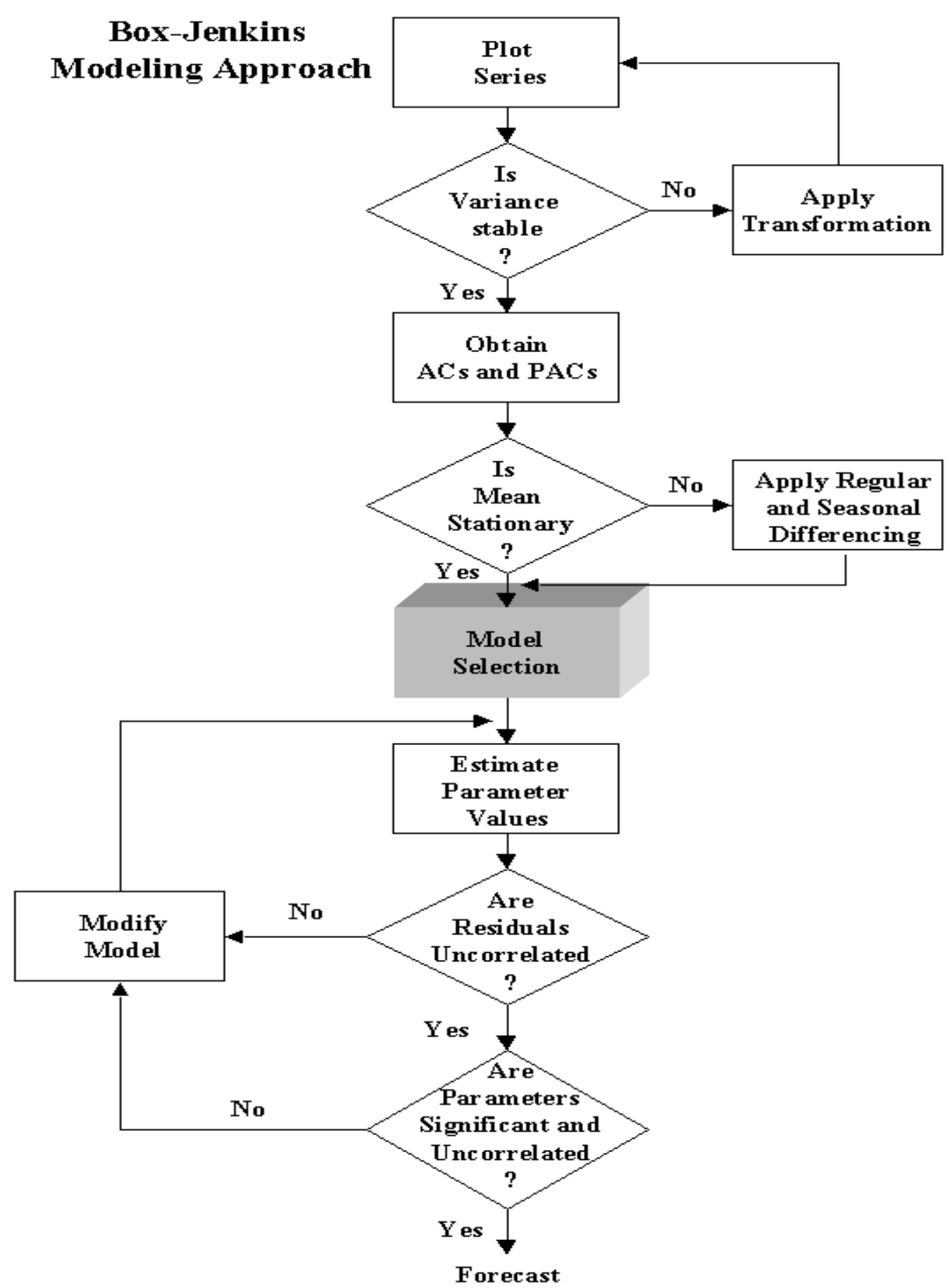

For testing the null hypothesis "data is not stationary", we use Augmented Dickey Fuller (ADF) test. If the significant value of ADF test is less than desired level of significance which is mostly 0.05 , we conclude that data is stationary.

The linear relationship between two values of the similar variable is terms as autocorrelation (ACF). If we determine ACF after removing any linear dependency from the lag values, it will have called partial autocorrelation (PACF). ACF and PACF both ranges from -1 to +1 . The graphical representation of ACF and PACF is called Correlogram. In the correlogram ACF show the order of autoregressive model (p) and PACF show the order of moving average model (q). 


\section{Results and Discussion:-}

For the forecasting purpose, data is taken from the site of Index mundi and it consists of the yearly wheat production in Pakistan and India (1000MT) from 1960 to 2015.

\section{Stationary Test:-}

When the variable is without any modification of its average value and variation for a long time, is said stationary. For using the Box-Jenkins methodology, variable must be stationary. In the literature numerous charts and empirical methods, available to verify stationary. In this study, both graphics and empirical methods were used for these purposes. Figure 1 shows the line chart of wheat production of Pakistan and India from 1960 to 2015. Figure 2 shows correlogram for yearly wheat production.

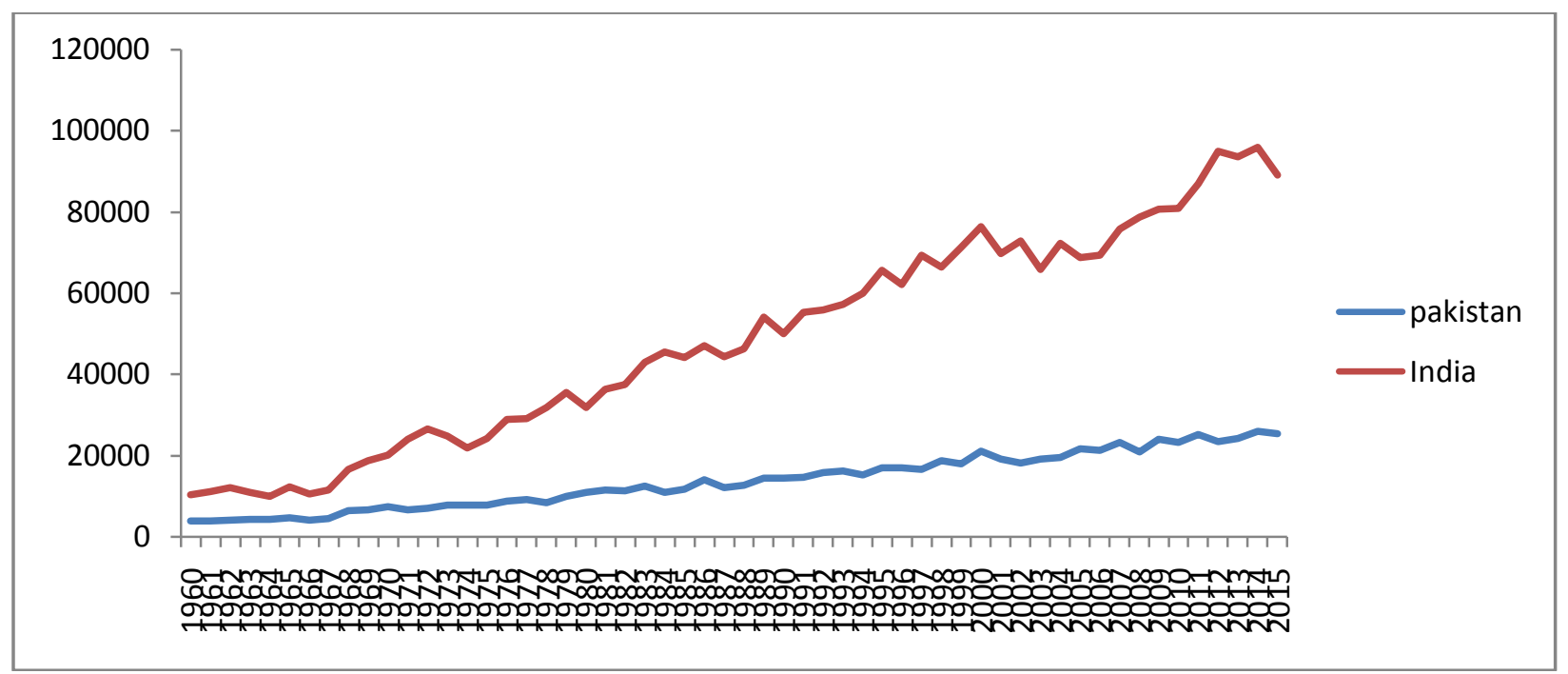

Figure 1. Yearly wheat production

Figure 1 shows time on $\mathrm{x}$-axis and wheat production on y axis. The pattern reveals that there are many ups and downs in the wheat production in both countries. Long term increasing pattern of wheat production indicates that it is non stationary. It also shows that long run increase in production is rapid in India as compare to Pakistan. 
Pakistan

\begin{tabular}{|c|c|c|c|}
\hline Autocorrelation & Partial Correlation & $A C \quad P A C$ & Q-Stat Prob \\
\hline 15 & $1 E$ & $\begin{array}{lll}1 & 0.936 & 0.936\end{array}$ & 51.7720 .000 \\
\hline $1=$ & 101 & $20.884 \quad 0.063$ & 98.8210 .000 \\
\hline 15 & 11 & $30.835-0.003$ & 141.500 .000 \\
\hline $1 \square$ & 11 & $40.787-0.001$ & 180.240 .000 \\
\hline $1 \square$ & 10 1 & $\begin{array}{lll}5 & 0.729 \cdot 0.118\end{array}$ & $214.04 \quad 0.000$ \\
\hline $1 \square$ & $1] 1$ & $\begin{array}{llll}6 & 0.677 & 0.008\end{array}$ & 243.790 .000 \\
\hline $1 \square$ & 101 & $70.617-0.090$ & $269.02 \quad 0.000$ \\
\hline $1 \square$ & 11 & $\begin{array}{lll}8 & 0.564 & 0.005\end{array}$ & 290.530 .000 \\
\hline $1 \square$ & 11 & 90.5160 .022 & 308.910 .000 \\
\hline $1 \square$ & 11 & $100.466 \cdot-0.048$ & 324.210 .000 \\
\hline $1 \square$ & $1 \mid 1$ & $110.418-0.001$ & 336.810 .000 \\
\hline । $\square$ & 11 & $12 \quad 0.371-0.032$ & 346.990 .000 \\
\hline । & $1 \mid 1$ & $13 \quad 0.326 \cdot-0.025$ & 355.000 .000 \\
\hline $1 \square$ & 101 & $\begin{array}{lll}14 & 0.288 & 0.038\end{array}$ & 361.430 .000 \\
\hline । & 101 & $15 \quad 0.241-0.114$ & 366.030 .000 \\
\hline اط ا & 101 & $\begin{array}{lll}16 & 0.183 & -0.127\end{array}$ & 368.740 .000 \\
\hline וp & 101 & $\begin{array}{lll}17 & 0.141 & 0.070\end{array}$ & 370.400 .000 \\
\hline 171 & 101 & $180.095-0.071$ & 371.180 .000 \\
\hline 101 & 11 & 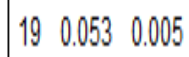 & 371.420 .000 \\
\hline 11 & 11 & 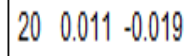 & 371.440 .000 \\
\hline 11 & 11 & $21-0.026-0.018$ & 371.500 .000 \\
\hline 1 & 101 & $22 \cdot-0.059 \quad 0.029$ & $371.83 \quad 0.000$ \\
\hline 101 & 101 & $23-0.095-0.097$ & 372.710 .000 \\
\hline 10 1 & $1 \mid 1$ & $\begin{array}{ccc}24 & -0.126 & 0.008\end{array}$ & 374.330 .000 \\
\hline
\end{tabular}

\section{India}

\begin{tabular}{|c|c|c|c|c|c|}
\hline \multicolumn{2}{|c|}{ Autocorrelation } & \multicolumn{2}{|c|}{ Partial Correlation } & $A C \quad P A C$ & Q-Stat Prob \\
\hline 1 & & 1 & & $\begin{array}{lll}1 & 0.947 & 0.947\end{array}$ & 53.0090 .000 \\
\hline 1 & & 10 & I & $20.892 \cdot 0.053$ & 100.890 .000 \\
\hline 1 & Z & 1 & 1 & $30.835 \cdot 0.053$ & $143.58 \quad 0.000$ \\
\hline 1 & E & 10 & 1 & $40.771-0.085$ & 180.740 .000 \\
\hline 1 & $\square$ & 1 & 1 & $\begin{array}{lll}50.717 & 0.053\end{array}$ & 213.470 .000 \\
\hline 1 & $\square$ & 11 & 1 & $60.665-0.011$ & 242.160 .000 \\
\hline 1 & $\square$ & 1 & 1 & $70.612 \cdot 0.035$ & 267.000 .000 \\
\hline 1 & $\square$ & 10 & 1 & $80.559-0.050$ & 288.160 .000 \\
\hline 1 & $\square$ & 1 & 1 & 90.5120 .028 & 306.250 .000 \\
\hline 1 & $\square$ & 1 & 1 & $\begin{array}{llll}10 & 0.475 & 0.073\end{array}$ & 322.150 .000 \\
\hline 1 & $\square$ & 1 | & 1 & $\begin{array}{lll}11 & 0.436 & -0.047\end{array}$ & 335.890 .000 \\
\hline 1 & $\square$ & I & 1 & $\begin{array}{lll}12 & 0.395 & -0.069\end{array}$ & 347.410 .000 \\
\hline 1 & $\square$ & 1 & 1 & $\begin{array}{lll}13 & 0.361 & 0.041\end{array}$ & 357.270 .000 \\
\hline 1 & $\square$ & I & 1 & $14 \quad 0.313 \cdot 0.150$ & 364.840 .000 \\
\hline 1 & $\square$ & 10 & 1 & $150.262 \cdot 0.060$ & 370.270 .000 \\
\hline 1 & | & 10 & 1 & $160.204-0.111$ & 373.670 .000 \\
\hline 1 & । & 1 & 1 & $\begin{array}{lll}17 & 0.153 & 0.046\end{array}$ & 375.620 .000 \\
\hline 1 & 1 & 1 & 1 & $\begin{array}{ll}18 & 0.106 \\
-0.0005\end{array}$ & 376.580 .000 \\
\hline 1 & 1 & 10 & 1 & $190.055-0.082$ & 376.850 .000 \\
\hline 1 & 11 & 1 & 1 & $\begin{array}{lll}20 & 0.014 & 0.023\end{array}$ & 376.870 .000 \\
\hline 1 & 1 & 10 & 1 & $21-0.034-0.101$ & $376.98 \quad 0.000$ \\
\hline 1 & 1 & 1 & 1 & $\begin{array}{llll}22 & -0.077 & 0.031\end{array}$ & $377.54 \quad 0.000$ \\
\hline 1[ & [ 1 & 11 & 1 & $23-0.113-0.034$ & 378.800 .000 \\
\hline I & 1 & 11 & 1 & $24-0.148 \cdot-0.030$ & 381.010 .000 \\
\hline
\end{tabular}

Figure2:-Correlogram for yearly wheat production.

In Figure 2, Correlogram shows that there is high correlation between the values, but with the passage of time it decreases but still shows significant behavior.

In empirical methods, ADF (Augmented-Dickey Fuller) test has been utilized. On the basis of its ADF values 0.580382, 0.073287 for Pakistan and India respectively, we don't reject our H0 at the $5 \%$ level of significance. In this study, differenced technique is utilized to make variable stationary. Line chart, Correlogram and ADF test have been utilized again after taking 1 st difference of variable. 


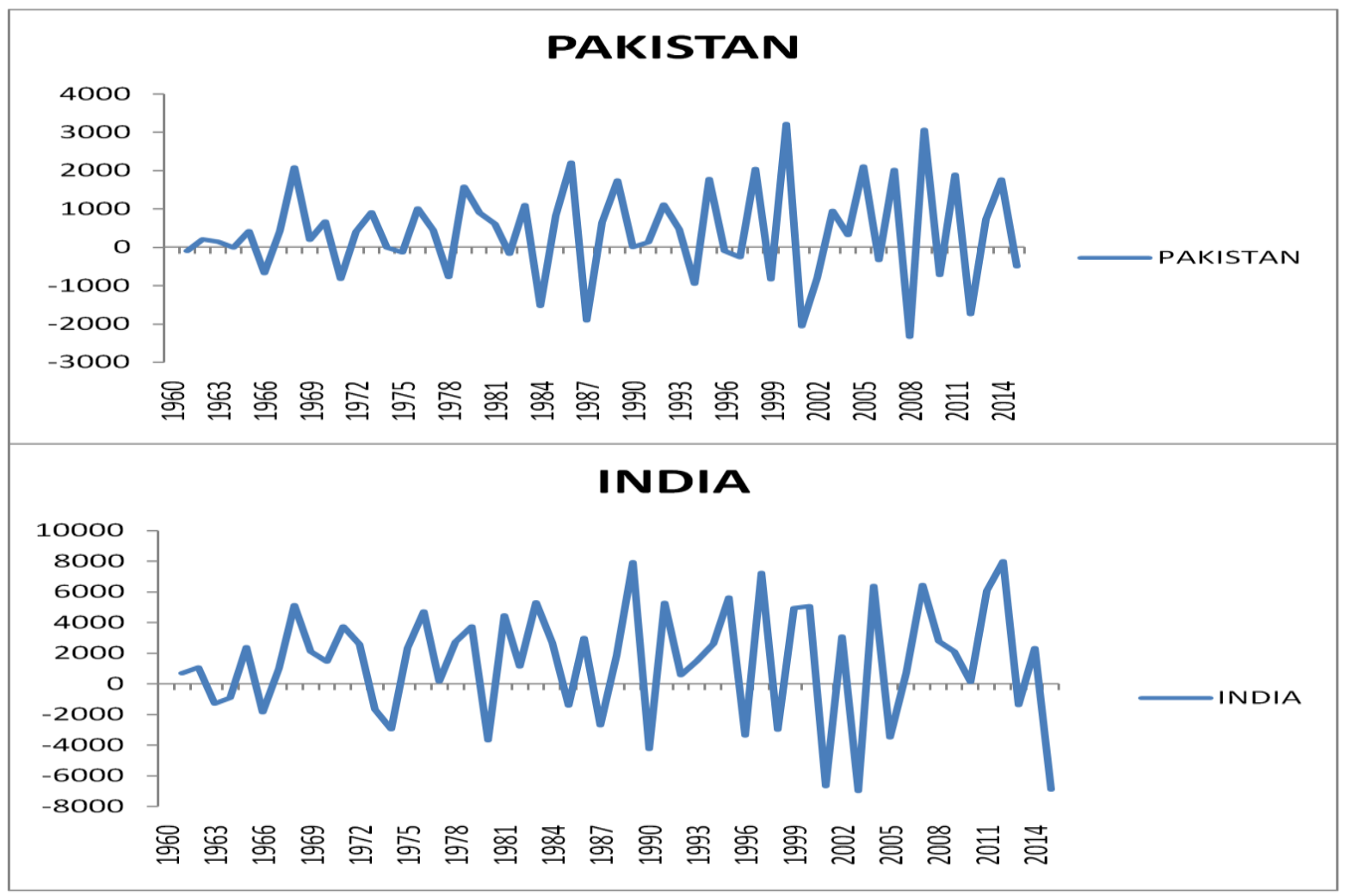

Figure 3:-Line chart of wheat production in Pakistan and India at 1st Difference.

Line chart of the yearly wheat production by using the 1st difference is shown in Figure 3. It shows that the mean of wheat production has no change so it has constant variation throughout the time period. We may say that series is stationary at 1 st difference.

\begin{tabular}{|c|c|c|c|c|c|c|c|c|c|c|c|c|c|}
\hline \multicolumn{8}{|c|}{ Pakistan } & \multicolumn{6}{|c|}{ India } \\
\hline Autocorrelation & Partial Co & Correlation & $A C$ & PAC & Q-Stat & Prob & Autocorrelation & Partial Co & orrelation & $A C$ & PAC & Q-Stat & Prob \\
\hline$\square$ । & $\square$ & - 1 & $1-0.557$ & -0.557 & 18.040 & 0.001 & $\square$ । & $\square$ & 1 & $1-0.373$ & -0.373 & 8.0722 & 0.004 \\
\hline 1 & $\square$ & 1 & 20.116 & -0.282 & 18.839 & 0.001 & 1 & 1 & 1 & 20.144 & 0.006 & 9.2996 & 0.010 \\
\hline $1 \sqrt{1}$ & $\square$ & 1 & $3-0.061$ & -0.213 & 19.064 & 0.001 & $1 \sqrt{1}$ & 1 & 1 & $3-0.030$ & 0.029 & 9.3549 & 0.025 \\
\hline 1 & I맘 & 1 & 40.009 & -0.177 & 19.069 & $0.00^{\circ}$ & 미 । & 마 & 1 & $4-0.206$ & -0.243 & 11.973 & 0.018 \\
\hline 1 & 10 & 1 & $\begin{array}{ll}50.008 \\
\end{array}$ & -0.127 & 19.073 & $0.00 \%$ & וך & 10 & 1 & $\begin{array}{ll}5 & 0.194\end{array}$ & 0.046 & 14.323 & 0.014 \\
\hline 11 & 믐 & 1 & $6-0.049$ & -0.175 & 19.225 & 0.00 & 믄 & 10 & 1 & $6-0.230$ & -0.134 & 17.693 & 0.007 \\
\hline إط & 1 & יו & $\begin{array}{ll}7 & 0.194\end{array}$ & 0.129 & 21.681 & $0.00 \%$ & & 10 & 1 & $\begin{array}{ll}7 & 0.053\end{array}$ & -0.122 & 17.874 & 0.013 \\
\hline$\square$ । & 맘 & 1 & $8-0.337$ & -0.236 & 29.272 & 0.001 & 1 & 10 & 1 & $8-0.010$ & -0.053 & 17.880 & 0.022 \\
\hline $1 \square$ & 1 & 1 & 90.286 & -0.049 & 34.851 & 0.001 & 단 & 1 & 1 & $9-0.187$ & -0.219 & 20.252 & 0.016 \\
\hline$1 \longdiv { 1 }$ & 11 & 1 & $10-0.125$ & -0.021 & 35.941 & 0.001 & & 만 & 1 & $\begin{array}{ll}10 & 0.059\end{array}$ & -0.212 & 20.497 & 0.025 \\
\hline 171 & 1 & 1 & $\begin{array}{ll}11 & 0.084\end{array}$ & 0.055 & 36.447 & 0.001 & 1 & 17 & 1 & $\begin{array}{ll}11 & 0.011\end{array}$ & -0.012 & 20.506 & 0.039 \\
\hline $1[1$ & & 91 & $12-0.019$ & 0.109 & 36.474 & 0.001 & 1 & 1 & । & 120.014 & -0.059 & 20.521 & 0.058 \\
\hline 101 & & 1 & $13-0.081$ & -0.033 & 36.967 & 0.001 & । & 1 & 1 & $\begin{array}{ll}13 & 0.124\end{array}$ & 0.003 & 21.672 & 0.061 \\
\hline 1 & & p & $\begin{array}{ll}14 & 0.124\end{array}$ & 0.084 & 38.150 & 0.001 & 10 & 1 & ו & $14 \quad 0.039$ & 0.128 & 21.790 & 0.083 \\
\hline 101 & & מ & $15-0.084$ & 0.149 & 38.702 & $0.00^{\circ}$ & 101 & 10 & 1 & $15-0.086$ & -0.127 & 22.363 & 0.099 \\
\hline 11 & & 1 & $\begin{array}{ll}16 & 0.012\end{array}$ & -0.060 & 38.713 & $0.00^{\circ}$ & ו & 17 & 1 & $\begin{array}{ll}16 & 0.093\end{array}$ & -0.023 & 23.064 & 0.112 \\
\hline 1 & 1 & 1 & $\begin{array}{ll}17 & -0.024\end{array}$ & -0.002 & 38.759 & $0.00 \%$ & & 1 & 1 & $\begin{array}{ll}17 & -0.050\end{array}$ & 0.063 & 23.268 & 0.141 \\
\hline 1 & & 1 & $\begin{array}{ll}18 & 0.033\end{array}$ & -0.033 & 38.853 & 0.00 : & & 1 & 1 & $\begin{array}{ll}18 & 0.039\end{array}$ & -0.016 & 23.400 & 0.176 \\
\hline 101 & & י & 190.044 & 0.120 & 39.022 & 0.00 & 101 & 1 & 1 & 190.017 & 0.017 & 23.426 & 0.219 \\
\hline 101 & & 1 & $20-0.107$ & -0.029 & 40.039 & 0.00 ? & I & 1 & 1 & $20-0.159$ & -0.069 & 25.686 & 0.176 \\
\hline । & 1 & 1 & 210.150 & 0.042 & 42.113 & 0.00 & 1 & 1 & 1 & $21 \quad 0.129$ & 0.020 & 27.226 & 0.164 \\
\hline 101 & 1 & 1 & $22-0.128$ & 0.060 & 43.676 & 0.00 & Iㄴ. & 10 & 1 & $22-0.181$ & -0.064 & 30.330 & 0.111 \\
\hline 11 & 1 & 1 & $23-0.009$ & -0.104 & 43.683 & 0.006 & ום 1 & 1 & י & $\begin{array}{ll}23 & 0.175\end{array}$ & 0.166 & 33.339 & 0.075 \\
\hline 101 & 10 & 1 & 240.064 & -0.065 & 44.099 & $0.00 i$ & 101 & 1 & 1 & $24-0.066$ & -0.023 & 33.776 & 0.089 \\
\hline
\end{tabular}

Figure 4:-Correlogram of wheat production at 1st Difference 
Correlogram of the yearly wheat production by using the 1st difference is shown above in Figure 4. It clearly indicates that all spikes are random and very small in magnitude, so, our data is stationary.

When we apply ADF test on 1st difference data it shows ADF values $-8.365612,-10.53668$ for yearly wheat production of Pakistan and India respectively. So we reject our $\mathrm{H} 0$ at the $5 \%$ level of significance. We conclude that our data is stationary at the 1 st difference.

Model Identification and Parameter Estimation:-

Table 1:-AIC and SBC of Different ARIMA Models

Pakistan

\begin{tabular}{|c|c|c|}
\hline Models & AIC & SBC \\
\hline $0,1,1$ & $16.45914 *$ & $16.53213^{*}$ \\
\hline $1,1,0$ & 16.76689 & 16.84055 \\
\hline $1,1,1$ & $16.47323^{* *}$ & $16.58373^{* *}$ \\
\hline $1,1,2$ & 16.67879 & 16.78929 \\
\hline $1,1,3$ & 16.80320 & 16.91370 \\
\hline $2,1,0$ & 17.15058 & 17.22493 \\
\hline $3,1,0$ & 17.18048 & 17.25553 \\
\hline $0,1,2$ & 17.11410 & 17.18710 \\
\hline $0,1,3$ & 17.12409 & 17.19708 \\
\hline
\end{tabular}

India

\begin{tabular}{|c|c|c|}
\hline Models & AIC & SBC \\
\hline $0,1,1$ & $19.18484^{*}$ & $19.25783^{*}$ \\
\hline $0,1,2$ & 19.30213 & 19.37512 \\
\hline $1,1,0$ & $19.19033^{* *}$ & $19.26400^{* *}$ \\
\hline $1,1,1$ & 19.22727 & 19.33776 \\
\hline $1,1,2$ & 19.22734 & 19.33784 \\
\hline $1,1,3$ & 19.20639 & 19.31689 \\
\hline $2,1,0$ & 19.35408 & 19.42843 \\
\hline $3,1,0$ & 19.38631 & 19.46136 \\
\hline $4,1,0$ & 19.34665 & 19.42240 \\
\hline $0,1,3$ & 19.33601 & 19.40900 \\
\hline
\end{tabular}

** Second lowest value of AIC and SBC, *lowest value of AIC and SBC.

\section{Forecasting Accuracy:-}

India:-

For forecasting purposes ARIMA $(0,1,1)$ and ARIMA $(1,1,0)$ models are utilized.

$\widehat{D(w p)}=C+\alpha A R(p)+\beta M A(q)+\mu_{i}$

Where $\widehat{D(w p)}$ is 1 st differenced series of the yearly wheat production, $\mathrm{C}$ is an intercept, $\alpha$ is coefficient of autoregressive lag values $\operatorname{AR}(p), \beta$ is coefficient of moving average lag values MA(q) and $\mu$ shows the residuals of model. In Box Jenkins model residuals should be independently identically normally distributed. In ARIMA $(1,1,0)$ we use AR (1) model so its estimated equation is.

$\widehat{D(w p)}=1484.408-0.411965 A R(1)$

In ARIMA $(0,1,1)$ we use MA (1) model so its estimated equation is.

$\widehat{D(w p)}=1504.174-0.409665 M A(1)$

For measuring the accuracy of these two models we use MAE, MAPE and RMSE.

Table2:-. Forecasting Checks

\begin{tabular}{|l|l|l|}
\hline & Model $(0,1,1)$ & Model $(1,1,0)$ \\
\hline RMSE & 5061.670 & 4723.810 \\
\hline MEA & 4339.441 & 3971.268 \\
\hline MAPE & 15.07795 & 13.82048 \\
\hline
\end{tabular}

Table 2 shows that MAE, MAPE, and RMSE of ARIMA $(1,1,0)$ model are less than ARIMA $(0,1,1)$ model. So, there is less error in forecast values of ARIMA $(1,1,0)$ than ARIMA $(0,1,1)$.

\section{Analysis of Forecast Results:-}

The yearly wheat production from 1960 until 2015 are used for forecasting the next 10 values of the yearly wheat production by using both ARIMA $(0,1,1)$ and ARIMA $(1,1,0)$ models. The forecasted results are following: 


\section{Model (0,1,1)}

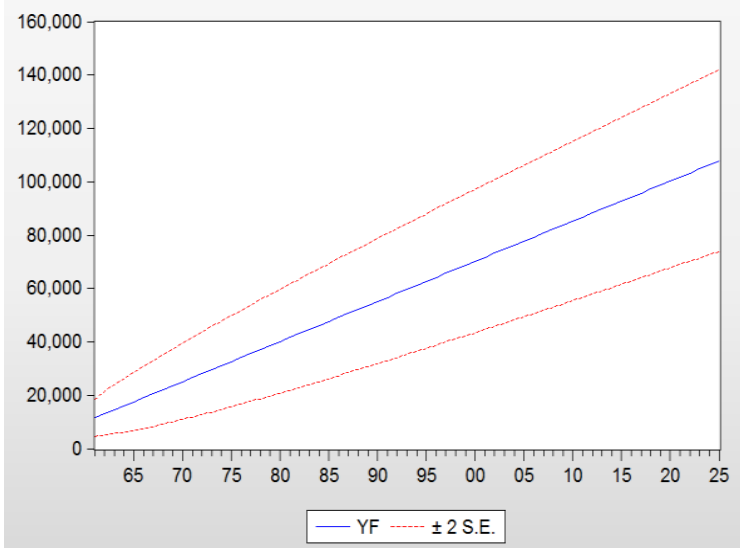

Model (1,1,0):-

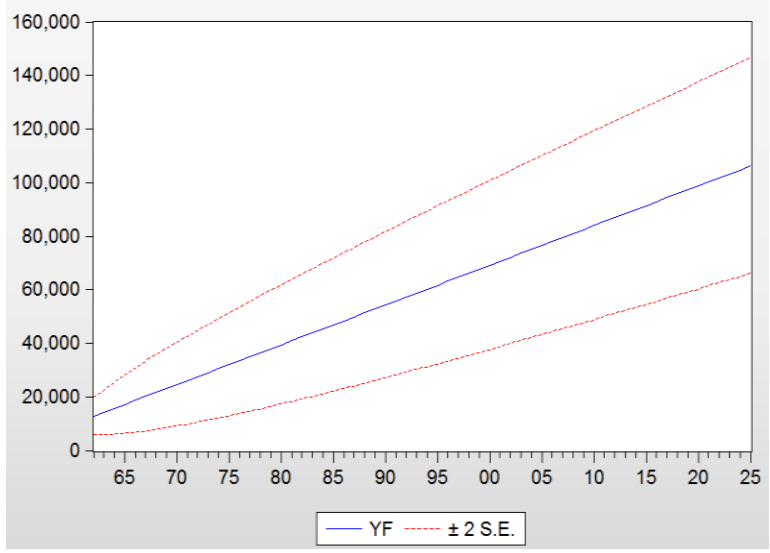

Figure 5:-Forecast Analysis

Figure 5 shows the forecast of ARIMA $(1,1,0)$ and ARIMA $(0,1,1)$ with 2 S.E. In the above figure year are taken on $\mathrm{x}$-axis and wheat production on $\mathrm{y}$ axis. It clearly shows that Forecast of ARIMA $(1,1,0)$ are better than ARIMA $(0,1,1)$ due to less MAE, MAPE, and RMSE.

\section{Pakistan:-}

In ARIMA $(1,1,0)$ we use AR (1) model so its estimated equation is.

$\widehat{D(w p)}=418.3928-0.97649 M A(1)$

In ARIMA $(1,1,1)$ we use AR (1) and MA (1) model so its estimated equation is.

$\widehat{D(w p)}=422.1590+.014448 A R(1)-.982480 M A(1)$

For measuring the accuracy of these two models we use MAE, MAPE and RMSE.

Table3:- Forecasting Checks.

\begin{tabular}{|l|l|l|}
\hline & Model $(1,1,1)$ & Model $(0,1,1)$ \\
\hline RMSE & 864.7578 & 881.1657 \\
\hline MEA & 704.3548 & 717.6435 \\
\hline MAPE & 6.400445 & 6.763847 \\
\hline
\end{tabular}

Table 3 shows that MAE, MAPE, and RMSE of ARIMA $(1,1,1)$ model are less than ARIMA $(0,1,1)$ model. So, there is less error in forecast values of ARIMA $(1,1,1)$ than ARIMA $(0,1,1)$.

\section{Analysis of Forecast Results:-}

The yearly wheat production from 1960 until 2015 are used for forecasting the next 10 values of the yearly wheat production by using both ARIMA $(1,1,1)$ and ARIMA $(1,1,0)$ models. The forecasted results are following: 


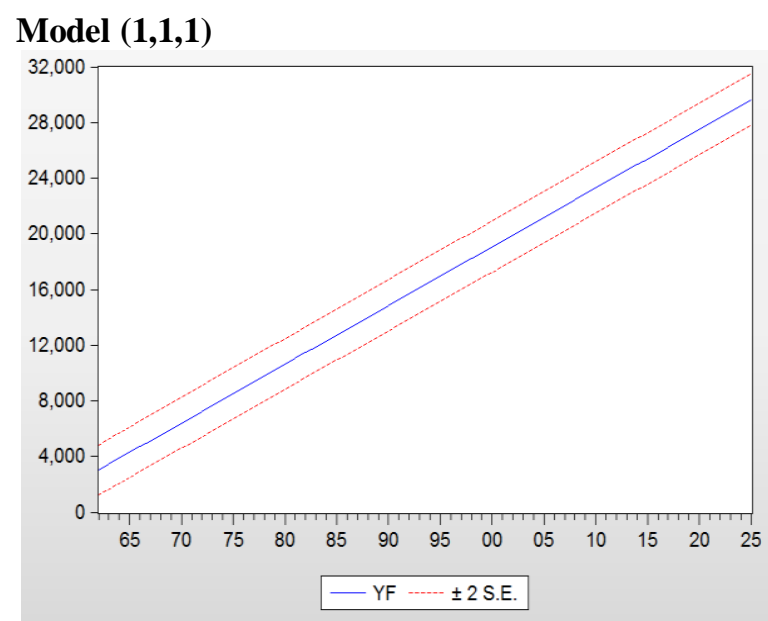

Figure 6:-Forecast Analysis

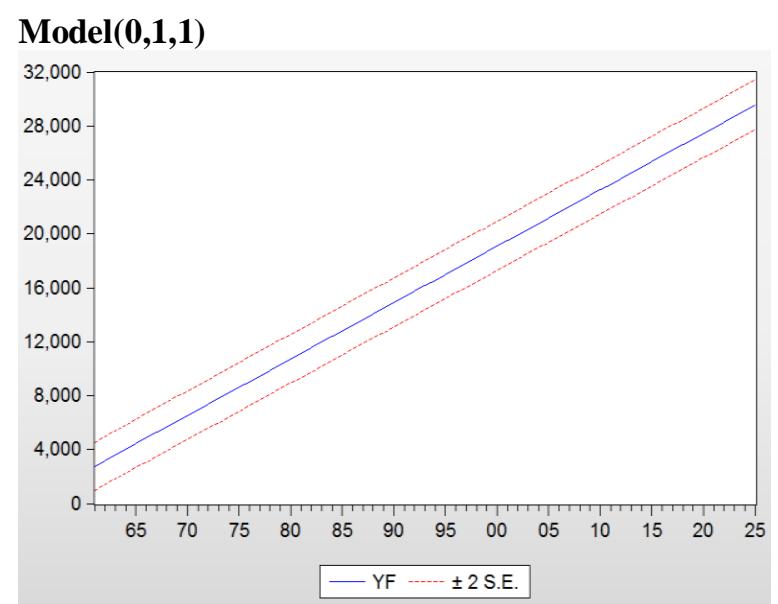

Figure 6 shows the forecast of ARIMA $(1,1,1)$ and ARIMA $(0,1,1)$ with 2 S.E. In the above figure year are taken on $\mathrm{x}$-axis and wheat production on $\mathrm{y}$ axis. It clearly shows that Forecast of ARIMA $(1,1,1)$ are better than ARIMA $(0,1,1)$ due to less MAE, MAPE, and RMSE.

\section{Residuals Analysis:-}

In the Box-Jenkins methodology, best equipped model residues should be independently identical normally distributed (IID). To justify this hypothesis, normality plot and correlogram are utilized.

India

\section{Pakistan}

\begin{tabular}{|c|c|c|c|c|c|}
\hline Autocorrelation & Partial Correlation & $A C$ & PAC & Q-Stat & Prob \\
\hline 101 & 101 & $1-0.078$ & -0.078 & 0.3455 & \\
\hline 1$] 1$ & $1] 1$ & 20.052 & 0.047 & 0.5044 & \\
\hline 101 & 101 & $3-0.054$ & -0.047 & 0.6790 & 0.410 \\
\hline 111 & 111 & $4-0.022$ & -0.033 & 0.7095 & 0.701 \\
\hline 111 & 111 & 50.011 & 0.012 & 0.7175 & 0.869 \\
\hline 101 & 101 & $\begin{array}{ll}6 & 0.051\end{array}$ & 0.054 & 0.8846 & 0.927 \\
\hline וב 1 & וב 1 & $\begin{array}{ll}7 & 0.139\end{array}$ & 0.144 & 2.1222 & 0.832 \\
\hline 田 & 叫 & $8-0.189$ & -0.178 & 4.4598 & 0.615 \\
\hline ום 1 & ום ו & $\begin{array}{ll}9 & 0.182\end{array}$ & 0.160 & 6.6881 & 0.462 \\
\hline 111 & 111 & $10-0.014$ & 0.040 & 6.7008 & 0.569 \\
\hline 1 1 & 101 & 110.074 & 0.052 & 7.0910 & 0.628 \\
\hline 111 & 111 & $12-0.024$ & -0.021 & 7.1324 & 0.713 \\
\hline 101 & 101 & $13-0.076$ & -0.093 & 7.5541 & 0.753 \\
\hline 121 & 1 & $14 \quad 0.072$ & 0.087 & 7.9458 & 0.789 \\
\hline 101 & 101 & $15-0.067$ & -0.034 & 8.2972 & 0.824 \\
\hline 101 & 101 & $16-0.051$ & -0.165 & 8.5004 & 0.862 \\
\hline \begin{tabular}{l|l}
1 & 1
\end{tabular} & 101 & $17-0.004$ & 0.050 & 8.5017 & 0.902 \\
\hline 101 & 111 & $\begin{array}{ll}18 & 0.062\end{array}$ & 0.042 & 8.8276 & 0.920 \\
\hline 101 & 101 & $\begin{array}{ll}19 & 0.039\end{array}$ & 0.073 & 8.9618 & 0.941 \\
\hline 101 & 101 & $20-0.096$ & -0.145 & 9.7749 & 0.939 \\
\hline 111 & 101 & $21 \quad 0.011$ & -0.036 & 9.7870 & 0.958 \\
\hline 回 1 & 101 & $22-0.210$ & -0.116 & 13.972 & 0.832 \\
\hline 101 & 吗 1 & $23-0.113$ & -0.174 & 15.224 & 0.812 \\
\hline 111 & 101 & $\begin{array}{ll}24 & 0.011\end{array}$ & -0.027 & 15.237 & 0.852 \\
\hline
\end{tabular}

\begin{tabular}{|c|c|c|c|c|c|c|c|}
\hline \multicolumn{2}{|c|}{ Autocorrelation } & \multicolumn{2}{|c|}{ Partial Correlation } & $A C$ & PAC & Q-Stat & Prob \\
\hline । & 1 & I & 1 & $1-0.004$ & -0.004 & 0.0009 & \\
\hline 1 & 1 & 1 & 1 & $2-0.004$ & -0.004 & 0.0018 & 0.967 \\
\hline 10 & 1 & 10 & 1 & $3-0.079$ & -0.079 & 0.3748 & 0.829 \\
\hline I & 1 & I & 1 & $4-0.161$ & -0.163 & 1.9480 & 0.583 \\
\hline 10 & 1 & 1 & 1 & $\begin{array}{ll}50.073 \\
5\end{array}$ & 0.071 & 2.2770 & 0.685 \\
\hline 맘 & 1 & 吅 & 1 & $6-0.207$ & -0.221 & 4.9708 & 0.419 \\
\hline 10 & 1 & 10 & 1 & $7-0.034$ & -0.064 & 5.0440 & 0.538 \\
\hline 10 & 1 & 10 & 1 & $8-0.058$ & -0.087 & 5.2624 & 0.628 \\
\hline 맘 & 1 & 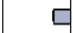 & 1 & $9-0.207$ & -0.250 & 8.1555 & 0.418 \\
\hline 11 & 1 & 10 & 1 & $10-0.015$ & -0.135 & 8.1719 & 0.517 \\
\hline 1 & 1 & 1 & 1 & 110.038 & 0.002 & 8.2718 & 0.602 \\
\hline 1 & 1 & 10 & 1 & $\begin{array}{ll}12 & 0.091\end{array}$ & -0.047 & 8.8631 & 0.635 \\
\hline 1 & ا & 1 & 1 & 130.148 & 0.044 & 10.469 & 0.575 \\
\hline 1 & 1 & 1 & 1 & 140.061 & 0.050 & 10.750 & 0.632 \\
\hline 10 & 1 & 맘 & 1 & $15-0.087$ & -0.191 & 11.344 & 0.659 \\
\hline 1 & 1 & 1 & 1 & $\begin{array}{ll}16 & 0.089\end{array}$ & 0.073 & 11.977 & 0.681 \\
\hline 1 & 1 & 1 & 1 & 170.004 & 0.022 & 11.979 & 0.745 \\
\hline । & 1 & 10 & 1 & 180.030 & -0.038 & 12.053 & 0.797 \\
\hline 1 & 1 & 1 & 1 & $19-0.020$ & -0.008 & 12.087 & 0.843 \\
\hline I & 1 & 10 & 1 & $20-0.166$ & -0.088 & 14.529 & 0.752 \\
\hline 1 & 1 & 1 & 1 & 210.039 & -0.000 & 14.668 & 0.795 \\
\hline 10 & 1 & 1 & 1 & $22-0.091$ & -0.014 & 15.449 & 0.800 \\
\hline 1 & 21 & & | & 230.124 & 0.149 & 16.953 & 0.766 \\
\hline 11 & | 1 & 10 & & $24-0.005$ & -0.094 & 16.956 & 0.811 \\
\hline
\end{tabular}

Figure 7:-Correlogram of Residuals

Correlogram of residuals indicates that they are stationary in nature and have no pattern. 
Pakistan

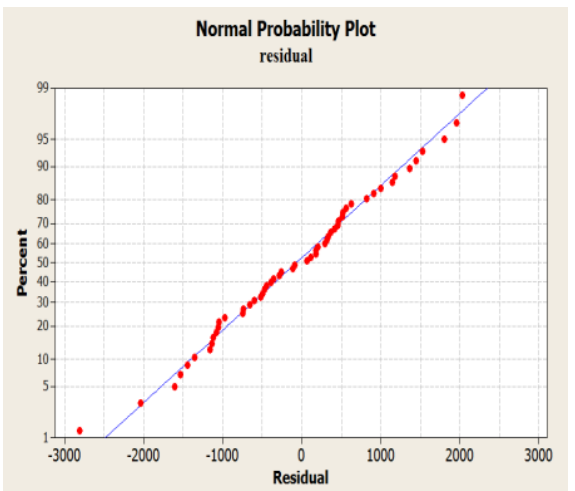

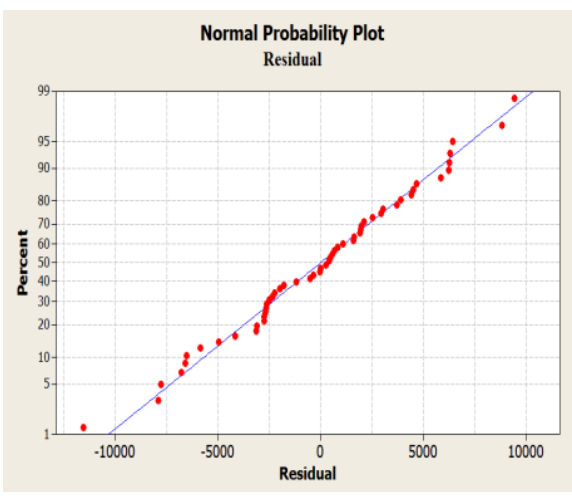

Figure8:-Normal Probability Plot of Residuals

\section{India}

The normality plot shows that residuals of ARIMA $(1,1,1)$ and ARIMA $(1,1,0)$ are normally distributed as the residuals close to the line. So, Normality plot and Correlogram tells that the selected model ARIMA $(1,1,1)$ and ARIMA $(1,1,0)$ are best for the forecasting purpose of yearly wheat production of Pakistan and India respectively.

\section{Conclusion:-}

As the population increases over time regularly, therefore it is necessary to plan to meet the requirements of nation. For this purpose, forecasting is the key tool to alarm about the need of nation in advance. Wheat is the basic need of any country all over the world. In this study, we developed time series models to forecasts wheat production of Pakistan and India on the basis of historical data i.e. 1960-2015. We have developed different time series models on wheat production of Pakistan and India on this data. Best model is selected on the basis of model selection criteria i.e. AIC and SBC. Main interest of developing time series model is that the model fitted is also satisfied residual assumptions i.e. normality, independence and no autocorrelation. On the basis of these model selection criteria, we have found that best model for wheat production forecasting of Pakistan and India are ARIMA $(1,1,1),(0,1,1)$ respectively because these models have lower AIC and SBC as compared to other fitted time series models. On the basis of these models, we have found that wheat production of Pakistan would become 27623.5 thousand tons in 2020 and would become double in 2060 as compared in 2010 under the assumption that there is no irregular movement or variation is occurred.

\section{References:-}

1. Muhammad, F., Siddique, M., Bashir, M., and Ahmad, S. (1992). Forecasting Rice Production in Pakistan using ARIMA Models. J.Anim.Plant.Sci. 2: 27-31.

2. Saeed, N., Saeed, A., Zakria, M., and Bajwa, T. (2000). Forecasting of Wheat Production in Pakistan using ARIMA model. Journal of Agriculture \& Biology. 2(4): 352-353.

3. Shah, M., Mumtaz, K., and Atta, A. (2001). Comparative Study of Wheat Production before and after Chashma Right Bank Canal. Journal of Managerial Sciences. 4(1).

4. Iqbal, N., Bakhsh, K., Maqbool, A., and Ahmad, A. S. (2005). Use of the ARIMA Model for Forecasting Wheat Area and Production in Pakistan. Journal of Agriculture \& Social Sciences. 1(2):120-122.

5. Karim, R., Awal, A., and Akhter, M. (2005). Forecasting of Wheat Production in Bangladesh. J. Agri. Soc. Sci. 1: $120-122$.

6. Amin, M., Amanullah. M, and Akbar. A. (2014). Time Series Modeling for Forecasting Wheat Production of Pakistan. The Journal of Animal \& Plant Sciences, 24(5): 1444-1451.

7. Choudhury, A., and Jones, J. (2014). CROP YIELD PREDICTION USING TIME SERIES MODELS. Journal of Economic and Economic Education Research. 15(3).

8. Iqbal, M., Hussain, Z., and Mahmood, T. (2014). Forecasting Trade Behaviour of Major food Crops in Four Leading SAARC Countries. Pakistan Economic and Social Review. 52(2): 209-226.

9. Ali, S., and Jabbar, A. (2015). Growth and Variability in Area Production and Yield of Selected Fruit Crops in Khyber Pakhtunkhwa. Pakistan J. Agric, Res. 28(1).

10. Ramesh, D., Soumen, P., and Srinivasa, V. R. (2015). Time Series Modeling for Trend Analysis and Forecasting Wheat Production of India. International Journal of Agriculture, Environment \& Biotechnolog, 8: 303. 